\title{
DNA replication and smooth muscle cell hypertrophy
}

\author{
Kenneth Walsh, ${ }^{1,2}$ Ichiro Shiojima, ${ }^{1}$ and Antonio Gualberto ${ }^{1,3}$ \\ ${ }^{1}$ Division of Cardiovascular Research, St. Elizabeth's Medical Center, Tufts University School of Medicine, Boston, Massachusetts 02135, USA \\ ${ }^{2}$ Program in Cell, Molecular and Developmental Biology, Tufts University, Sackler School of Biomedical Studies, Boston, Massachusetts 02135, USA \\ ${ }^{3}$ Central Research Division, Pfizer Inc., Groton, Connecticut 06340, USA
}

Address correspondence to: Kenneth Walsh, Division of Cardiovascular Research, St. Elizabeth's Medical Center, 736 Cambridge Street, Boston, Massachusetts 02135, USA. Phone: (617) 562-7501; Fax: (617) 562-7506; E-mail: kwalsh@opal.tufts.edu or kwalsh@world.std.com.

Vascular smooth muscle cell (VSMC) hypertrophy is the main cause of largevessel noncompliance in elderly and hypertensive individuals. VSMC hypertrophy, as strictly defined, is an increase in cell size without associated increases in cell number. This process is associated with an increase in extracellular matrix deposition and an irreversible modulation of VSMC phenotype. VSMC hypertrophy has detrimental effects on vascular remodeling, with consequences on the circulation and metabolic demands of the left ventricle. Ultimately, VSMC hypertrophy can lead to systolic hypertension, altered coronary perfusion, and hypertrophy of the left ventricle. It also contributes to mortality associated with end-stage renal failure. These circumstances stress the need to develop a detailed understanding of the molecular mechanisms that underlie the onset of VSMC hypertrophy.

In the article by Braun-Dullaeus et al. in this issue of the JCI (1), new insights about VSMC hypertrophy are derived from analyses of the cyclin-dependent kinase (Cdk) inhibitor $\mathrm{p}^{2} 7^{\text {Kip1 }}$ in angiotensin II-stimulated cells in vitro. The Cdk's function to control cellular proliferation through their association with activating subunits, referred to as cyclins, whose levels are temporally regulated during the cell cycle. Cdk activities are also regulated through association with inactivating subunits, referred to as Cdk inhibitors. In cellular differentiation, the postmitotic state is achieved, in large part, by the upregulation of Cdk inhibitors that arrest cellcycle activity. In addition to these developmental cues, Cdk inhibitor expression is also controlled by environmental conditions that modulate cell growth, including exposure to $\gamma$ irradiation, cell-cell contact, and cytokine stimulation. The $\mathrm{Cdk}$ inhibitor $\mathrm{p} 27^{\mathrm{Kip} 1}$ and its homologues $\mathrm{p} 21^{\mathrm{Cip} 1}$ and $\mathrm{p} 57^{\mathrm{Kip} 1}$ have a broad speci- ficity for Cdk's, and they inhibit activity by forming higher-order complexes with the cyclin/Cdk holoenzyme. In VSMCs, the Cdk inhibitors p $27^{\text {Kip } 1}$ and p21 ${ }^{\text {Cip } 1}$ have previously been implicated in terminating VSMC proliferation in intimal lesions $(2,3)$.

Braun-Dullaeus et al. provide compelling evidence that suggests that p27 Kip1 functions as a molecular switch in determining whether VSMCs undergo hypertrophy or hyperplasia in response to external stimuli. Their experiments show that various cyclins and Cdk's are upregulated in response to both angiotensin II, which induces hypertrophy, and serum, which induces hyperplasia. However, levels of p27 $7^{\text {Kip } 1}$ decline in serum-treated cells but not in angiotensin II-treated cells. Moreover, it is shown that angiotensin II does not increase Cdc2 or Cdk2 activity, consistent with a cell-cycle block. To provide causal evidence that p27 $^{\text {Kip } 1}$ controls VSMC hypertrophy, the investigators first show that VSMC hypertrophy could be induced in serum-stimulated cells when $\mathrm{p} 27^{\mathrm{Kip}} 1$ is overexpressed. In critical experiments, antisense oligonucleotides were used to ablate $\mathrm{p} 27^{\text {Kip } 1}$ expression. Acute $\mathrm{p} 27^{\mathrm{Kip} 1}$ ablation blocked hypertrophy and promoted hyperplasia in VSMCs upon incubation with angiotensin II. Simply said, this study suggests that VSMC hypertrophy is a consequence of growth stimulation when cell-cycle progression is blocked.

The observations of Braun-Dullaeus et al. in cultured VSMCs are consistent with the phenotype of the $\mathrm{p} 27^{\text {Kip } 1}$ knockout mouse. These mice contain enlarged organs that are comprised of an increased number of cells that, surprisingly, are smaller than corresponding cells from the wild-type mouse (4, 5). Since, it has been shown that chronic stimulation of the renin-angiotensin system in rats will result in hypertension and VSMC hypertrophy (6), a pre- diction of the model put forth by Braun-Dullaeus et al. is that aging or renovascular hypertension would promote hyperplasia, rather than hypertrophy, in the capacitance vessels of p27 $7^{\text {Kip1 }}$ knockout mice. Such a study could provide important corroborative evidence for this hypothesis.

Although the observations of BraunDullaeus et al. significantly extend our understanding of VSMC hypertrophy, one must also acknowledge that their findings do not completely account for the VSMC phenotype observed in elderly and hypertensive patients and animals. For example, it has long been known that hypertrophic VSMCs are frequently polyploid, containing more than a diploid number of chromosomes (7). Although it has not been formally documented, hypertrophy-associated VSMC polyploidization probably arises from endoreplication, the reentry of cells with tetraploid DNA content into $\mathrm{S}$ phase. Therefore, Cdk inhibitors might be expected to inhibit polyploidization in VSMCs on the basis of their ability to block cell-cycle progression at G1 phase in tetraploid cells (8). Consistent with this hypothesis, it has been shown that loss of the Cdk inhibitor $\mathrm{p}^{2} 1^{\text {Cip } 1}$ leads to a disruption of cell-cycle checkpoint control and causes cells to accumulate polyploid nuclei $(8,9)$. Polyploidization in megakaryocytic cells is also associated with the downregulation of $\mathrm{p}^{2} 1^{\text {Cip } 1}$ and p27 $7^{\text {Kip }} 1$ (10). Furthermore, there may be a causal relationship between polyploidization and hypertrophy. Polyploid VSMCs have up to 5 times the mass and express twice as much extracellular matrix as their diploid counterparts $(7,11)$. This appears to be a general trait, as polyploidization in yeast is also associated with cell enlargement, which is attributed to lengthening of the G1 phase through suppression of G1 cyclins (12). Collectively, these find- 
ings suggest that other cell-cycle regulators may also participate in the hypertrophic process in VSMCs

In summary, Braun-Dullaeus et al. have put forth a new and interesting hypothesis regarding the mechanisms that underlie VSMC hypertrophy. However, many questions remain. For example, what is the relationship between p27 ${ }^{\text {Kip } 1}$ and polyploidization in VSMCs? Is there a causal relationship between VSMC polyploidization and hypertrophy? Furthermore, Ushio-Fukai et al. (13) recently reported that the serine/threonine protein kinase Akt 1 is essential for angiotensin II-induced VSMC hypertrophy. Thus, what is the relationship, if any, between $\mathrm{p} 27^{\mathrm{Kip} 1}$ and Akt 1 ? In view of recent advances in the understanding of molecular control mechanisms in DNA replication and hypertrophy, we anticipate rapid progress in this area.

1. Braun-Dullaeus, R., Mann, M., Ziegler, A., von der Leyen, H., and Dzau, V. 1999. A novel role for the cyclin-dependent kinase inhibitor $\mathrm{p}^{27^{\mathrm{Kip} 1}}$ in angiotensin II-stimulated vascular smooth muscle cell hypertrophy. J. Clin. Invest. 104: 815-823.

2. Chen, D., et al. 1997. Down-regulation of cyclindependent kinase activity and cyclin A promoter activity in vascular smooth muscle cells by $\mathrm{p} 27$ (KIP-1), an inhibitor of neointima formation in the rat carotid artery. J. Clin. Invest. 99:2334-2341.

3. Yang, Z.-Y., et al. 1996. Role of the p21 cyclindependent kinase inhibitor in limiting intimal cell proliferation in response to arterial injury. Proc. Natl. Acad. Sci. USA. 93:7905-7910.

4. Fero, M.L., et al. 1996. A syndrome of multiorgan hyperplasia with features of gigantism, tumorigenesis, and female sterility in $\mathrm{p}^{2} 7^{\mathrm{Kip} 1}$-deficient mice. Cell. 85:733-744.

5. Poolman, R., Li, J.-M., Durand, B., and Brooks, G. 1999. Altered expression of cell cycle proteins and prolonged duration of cardiac myocyte hyperpla-

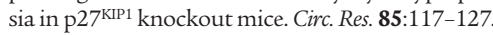
6. Owens, G., and Schwartz, S. 1983. Vascular smooth muscle cell hypertrophy and hyperploidy in the Goldblatt hypertensive rat Circ. Res. 53:491-501.

7. Owens, G., and Schwartz, S. 1982. Alterations in vascular smooth muscle mass in the spontaneously hypertensive rat. Circ. Res. 51:280-289.

8. Stewart, Z., Leach, S., and Pietenpol, J. 1999. $\mathrm{p} 21^{\text {Waf1/Cip } 1}$ inhibition of cyclin E/Cdk2 activity prevents endoreduplication after mitotic spindle disruption. Mol. Cell. Biol. 19:205-215.

9. Waldman, T., Lengauer, C., Kinzler, K., and Vogelstein, B. 1996. Uncoupling of S phase and mitosis induced by anticancer agents in cells lacking $\mathrm{p} 21$. Nature. 381:713-716.

10. Datta, N., Williams, J., and Long, M. 1998. Differential modulation of $\mathrm{G}_{1}$-S-phase cyclin-dependent kinase 2/cyclin complexes occurs during the acquisition of a polyploid DNA content. Cell Growth Differ. 9:639-650.

11. van Neck, J., et al. 1992. Effect of ploidy on transcription levels in cultured rat aortic smooth muscle cells. FEBS Lett. 297:189-195.

12. Galitski, T., Saldanha, A., Styles, C., Lander, E., and Fink, G. 1999. Ploidy regulation of gene expression. Science. 285:251-254.

13. Ushio-Fukai, M., et al. 1999. Reactive oxygen species mediate the activation of $\mathrm{Akt} /$ protein kinase B by angiotensin II in vascular smooth muscle cells. J. Biol. Chem. 274:22699-22704. 